\title{
KALABORASI PENGGUNAAN STRATEGI INFORMATION SEARCH (IS) DENGAN METODE RESITASI TERHADAP HASIL BELAJAR BIOLOGI SISWA DI SMP NEGERI 4 SUNGAI PENUH
}

\author{
Tomi Apra Santosa ${ }^{1}$, Reni Lestari ${ }^{2}$ \\ 1,2Pendidikan Biologi, Universitas Negeri Padang \\ E-mail : santosatomiapra@gmail.com
}

\begin{abstract}
Varied learning strategies and methods especially in the biological learning process used by teachers is still very limited. In the process of learning to teach teachers still use a method of discourse interspersed with discussion and question and answer. This research is quantitative research with experimental methods. Pupolasi used by all students of Grade VIII Junior High School 4 Sungai full consisting of 7 classes. Samples used in 2 classes, namely Classes VIII A and VIII B. Sampling techniques in random sampling. Instruments of research in the form of tests that first conducted the validity test, reliability, differentiation power, and index of tribulations. Data analysis techniques are a test of normality, homogeneity testing, and hypothesis testing. The results derived from this study are the outcomes of students who do not use the Information Search strategy through the method of Recitation, the highest value is 70 and the lowest 40. The average value of learning results in the 54.47 control class, while the results of the experimental classes that use the Infomation Search strategy through the method of recitation are better than the learning outcomes of the control class, where the highest value is 90 and the lowest value of 60 . The average value of the experimental class learning results is 75.78. The result of Thitung calculation is 6.83 This value is greater than 2.01. This shows the difference in learning outcomes between the experiment class and the control class. Because Thitung > This then $\mathrm{H} 1$ accepted.
\end{abstract}

Keywords : Strategy Information Search, Method of Recitation, Learning Outcomes

\begin{abstract}
ABSTRAK
Bervariasinya strategi dan metode pembelajaran khususnya dalam proses pembelajaran biologi yang digunakan guru masih sangat terbatas. Dalam proses belajar mengajar guru masih menggunakan metode ceramah yang diselingi dengan diskusi dan tanya jawab. Penelitian ini adalah penelitian kuantitatif dengan metode eksperimen. Pupolasi yang digunakan seluruh siswa kelas VIII SMP Negeri 4 Sungai Penuh yang terdiri dari 7 kelas. Sampel yang digunakan 2 kelas, yaitu kelas VIII A dan VIII B. Teknik pengambilan sampel secara random sampling. Intrumen penelitian berupa tes yang terlebih dahulu dilakukan uji validitas, reliabelitas, daya pembeda, dan indeks kesukaran. Teknik analisis data adalah uji normalitas, uji homogenitas, dan uji hipotesis. Hasil yang didapatkan dari penelitian ini adalah hasil belajar siswa yang tidak menggunakan strategi Information Search melalui metode resitasi, nilai tertinggi adalah 70 dan terendah 40 . Nilai rata-rata hasil belajar di kelas kontrol 54,47, sedangkan hasil belajar kelas eksperimen yang menggunakan strategi Infomation Search melalui metode resitasi lebih baik daripada hasil belajar kelas kontrol, dimana nilai tertinggi adalah 90 dan nilai terendah 60. Nilai rata-rata hasil belajar kelas eksperimen adalah 75,78. Hasil perhitungan thitung adalah sebesar 6,83 nilai ini lebih besar daripada tabel 2,01. Ini menunjukan adanya perbedaan hasil belajar antara kelas eksperimen dan kelas kontrol. Karena $t_{\text {hitung }}>t_{\text {tabel }}$ maka $\mathrm{H}_{1}$ diterima
\end{abstract}

Kata Kunci : Strategi Information Search, Metode Resitasi, Hasil Belajar

* Copyright (c) 2020 Tomi Apra Santosa et.all

This work is licensed under a Creative Commons Attribution-ShareAlike 4.0 International License. 
Khazanah Pendidikan Islam, Vol. 2 No. 2: 77-83

Kalaborasi Penggunaan Strategi Information Search (IS) Dengan Metode Resitasi Terhadap Hasil

Belajar Biologi Siswa di SMP Negeri 4 Sungai Penuh

Tomi Apra Santosa dan Reni Lestari

\section{PENDAHULUAN}

Perkembangan ilmu pengetahuan sekarang yang begitu cepat dunia pendidikan berbasis kepada teknologi. Semua itu agar mendorong guru untuk membuat suatu program pembelajaran yang terstruktur agar tercapai tujuan pembelajaran (Hoekstra, Beijaard, Brekelmans, Hoekstra, \& Beijaard, 2017). Pendidikan adalah sesuatu yang sangat penting dalam kehidupan manusia (Nurmiati1, 2019). Dengan pendidikan pola pikiran dan karakter setiap siswa dapat berkembang ketahap yang lebih baik. Dengan demikian, sistem pendidikan harus segera diperbaikan agar proses belajar mengajar berjalan dengan efektif dan efisien. Masalah pendidikan berhubungan erat dengan proses pembelajaran(Bahtiar, 2015). Pembelajaran adalah suatu kegiatan yang dilakukan secara sadar dan sengaja (Effendi, 2013). Pembelajaran harus menyentuh tiga konsep, yakni konsep inti disiplin (DCIs), ilmu pengetahuan dan pratik ( S\&EPS), dan konsep menyentuh (CCCs) (Friedrichsen, 2018). Guru yang menerapkan konsep tersebut harus merancang terlebih dahulu pemahaman tentang kurikulum agar dapat membantu siswa mencapai hasil belajar yang lebih baik. Guru harus berkomitmen untuk memajukan mata pelajaran disekolah dan proses belajar mengajar pada siswanya (Hallström, 2015).

Belajar adalah proses yang kompleks yang terjadi dalam diri setiap manusia sepanjang hidupnya (Eka Putri Azrai, Ernawati, 2017). Biologi merupakan cabang ilmu yang mempelajari tentang seluk beluk makhluk hidup. Siswa dituntut untuk bisa mengembang kerangka konseptual dan kemampuan berpikir dalam bidang pembelajaran termasuk biologi (Auerbach \& Andrews, 2018). Untuk mencapai semua itu guru harus menggunakan strategi dan model belajar yang tepat. Strategi merupakan cara yang akan digunakan guru dalam mengajar di kelas. Suatu strategi pembelajaran akan membantu kelancaran, efektivitas, dan efisiensi pencapaian tujuan (Rahmawati, 2014). Strategi pembelajaran adalah suatu set materi dan prosedur pembelajaran yang digunakan secara bersama-sama untuk menimbulkan hasil belajar pada siswa secara aktif dan partisipatif (Sintang \& Barat, 2018). Seseorang guru yang menerapkan strategi pembelajaran yang efektif akan berdampak besar terhadap hasil belajar siswa. Untuk meningkatkan hasil belajar siswa salah satu, yaitu dengan menerapkan strategi mencari informasi (Information Search). Strategi Information Seacrh adalah suatu strategi pembelajaran mencari informasi. Informasi dapat diperoleh melalui koran, buku paket, majalah atau internet.

Penelitian sebelumnya oleh Try Susanti, dkk (2017) menunjukan bahwa metode resitasi sangat berngaruh terhadap hasil belajar biologi siswa kelas XI SMA 1 Tanjung Jabung Timur di mana hasil $\mathrm{r}_{\text {hitung }}$ $\geq r_{\text {tabel }}$ pada taraf signifikansi $5 \%$ yaitu 0,265 $\geq 0,223$ (Try Susanti, et.al,. 2017), M.Irfan ( 2019) menunjukan bahwa penggunaan metode resitasi terhadap hasil belajar biologi sangat berpengaruh, di mana nilai rata-rata siswa yang menggunakan metode resitasi yaitu 80,24 lebih tinggi diandingkan ketika tidak menggunakan metode resitasi dengan nilai rata-rata yaitu 71,10 (Irfan, 2019), Bactiar Ismail \& Ismail Darimi (2016) menunjukan bahwa metode resitasi bisa meningkatkan hasil belajar mahasiswa serta dapat meningkatan pengauasaan terhadap mataeri hadist mahasiswa Pendidikan Agama Islam ArRaniri , yakni 67,06 lebih tinggi dibanding tidak menggunakan metode resitasi, yakni 65 (Ismail, 2016), Nurmiati, dkk (2019) menunjukan metode resitasi dapat meningkatkan hasil belajar mahasiswa dengan nilai rata-rata siswa, yakni 75,71 lebih tinggi, dibandingkan dengan mahasiswa tidak menggunakan metode resitasi dengan nilai rata-rata 59,28 (Nurmiati1,et,al., 2019). Dengan demikian, yang menjadikan perbedaan dari penelitian tedahulu, yakni penggunaan strategi Information Search (IS). Peneliti mengkalaborasikan penggunaan strategi Information Search dengan metode resitasi terhdap hasil belajar siswa biologi kelas VIII SMP Negeri 4 Sungai Penuh. Penelitian ini bertujuan untuk mengetahui bagaimana 
Khazanah Pendidikan Islam, Vol. 2 No. 2: 77-83

Kalaborasi Penggunaan Strategi Information Search (IS) Dengan Metode Resitasi Terhadap Hasil

Belajar Biologi Siswa di SMP Negeri 4 Sungai Penuh

Tomi Apra Santosa dan Reni Lestari

kalaborasi penggunaan strategi Information Search (IS) dengan metode pemberian tugas (resitasi) terhadap hasil belajar biologi siswa di kelas VIII SMP Negeri 4 Sungai Penuh.

\section{METODE PENELITIAN}

Penelitian ini adalah penelitian kuantitatif. Penelitian kuantitatif adalah penelitian yang menggunakan angka dalam peneyajian data dan analisis yang menggunakan uji statitika (Saebani, 2008). Metode yang digunakan adalah metode eksperimen model Posttest-Only Control Design. Populasi adalah himpunan keseluruhan karakteristik yang diteliti (Sedermayanti, 2011). Populasi dalam penelitian ini adalah seluruh mahasiswa kelas VIII SMP Negeri 4 Sungai Penuh yang yang terdiri dari 7 kelas 156 orang. Sampel adalah sebagian dari populasi(Prastowo, 2016). Sampel yang digunakan kelas VIII A dan VIII B. Teknik pengambilan sampel random sampling. Teknik analisis data adalah uji normalitas, uji homegenitas dan uji hipotesis.

\section{HASIL DAN PEMBAHASAN}

\section{Hasil Belajar Biologi Siswa yang Tidak Menggunakan Strategi Information Search Melalui Metode Resitasi}

Pada kelas kontrol, pengajaran berpusat pada guru sehingga siswa lebih banyak diam dan kurang aktif berpikir. Pembelajaran dilakukan dengan konvensional atau sama dengan pembelajaran dengan metode ceramah yang sifatnya hanya memberikan informasi kepada siswa, sehingga pembelajaran seperti ini tidak dapat memaksimalkan hasil belajar siswa. Di kelas kontrol peneliti memberikan pembelajaran materi gerak pada manusia sebanyak 3 kali, pembelajaran secara konvensional dengan tidak menggunakan strategi Information Search. Setelah diberi tes pada pertemuan terakhir hasil belajar, disajikan pada tabel 1 .

Tabel.I Hasil Belajar Biologi Kelas Kontrol

\begin{tabular}{|l|l|l|}
\hline No & Nomo Siswa & Skor Tes \\
\hline 1 & S-1 & 50 \\
\hline 2 & S-2 & 40 \\
\hline 3 & S-3 & 55 \\
\hline 4 & S-4 & 60 \\
\hline 5 & S-5 & 40 \\
\hline 6 & S-6 & 65 \\
\hline 7 & S-7 & 50 \\
\hline 8 & S-8 & 60 \\
\hline 9 & S-9 & 40 \\
\hline 10 & S-10 & 55 \\
\hline 11 & S-11 & 45 \\
\hline 12 & S-12 & 45 \\
\hline 13 & S-13 & 60 \\
\hline 14 & S-14 & 45 \\
\hline 15 & S-15 & 70 \\
\hline
\end{tabular}


Khazanah Pendidikan Islam, Vol. 2 No. 2: 77-83

Kalaborasi Penggunaan Strategi Information Search (IS) Dengan Metode Resitasi Terhadap Hasil Belajar Biologi Siswa di SMP Negeri 4 Sungai Penuh

Tomi Apra Santosa dan Reni Lestari

\begin{tabular}{|l|l|l|}
\hline 16 & S-16 & 70 \\
\hline 17 & S-17 & 50 \\
\hline 18 & S-18 & 70 \\
\hline 19 & S-19 & 55 \\
\hline 20 & S-20 & 60 \\
\hline 21 & S-21 & 50 \\
\hline 22 & S-22 & 40 \\
\hline
\end{tabular}

Dari tabel diatas terlihat bahwa hasil belajar siswa tidak menggunakan strategi Information Search masih banyak siswa yang nilainya dibawah KKM. Hal ini dikarenakan pelaksanaan pembelajaran di kelas kontrol guru hanya menyampaikan materi yang telah disiapkan.

Pada kelas kontrol yang tidak menggunakan strategi Information Search diperoleh nilai rata-rata hasil belajar biologi adalah 54,47 dengan nilai tertinggi 70 dan nilai terendah 40 .

\section{Hasil Belajar Biologi Siswa yang Menggunakan Strategi Information Search Melalui Metode Resitasi}

Berdasarkan tes hasil belajar yang dilaukan pada kelas eksperimen, diperoleh data nilai siswa. Data nilai siswa diperoleh dari hasil tes akhir. Pada strategi Infornation Search melalui resitasi guru mempersiapkan Rencana Pelaksanaa Pembelajaran (RPP) sebagai langkah awal pembelajaran. Pelaksanaan pembelajaran strategi Information Search melalui resitasi kelas dimulai dengan guru memberikan resitasi 10 butir soal essay tentang materi akan datang, kemudian siswa mencari informasi melalui berbagai media untuk menyelesaikan resitasi tersebut. Siswa mencatat jawaban soal-soa; yang dapat pada buku tugas, serta menulis sumber yang digunakan pada akhir jawaban. Sumber yang digunakan majalah, buku tesk dan informasi dari internet.Setelah semua materi selesai, guru melakukan evaluasi hasil akhir dengan melakukan tes hasil akhir kepada siswa. setelah dilakukakn evaluasi, diperoleh data hasil belajar pada kelas eksperimen yaitu kelas yang menggunakan strategi Information Search melalui resitasi pada pokok bahasan sistem gerak pada manusia. setelah semua selesai, diperoleh data hasil siswa kelas eksperimen , disajikan pada tabel 2.

Tabel.2 Hasil Belajar Biologi Kelas Eksperimen

\begin{tabular}{|c|c|c|}
\hline No & Nomor Siswa & Skor Tes \\
\hline 1 & S-1 & 60 \\
\hline 2 & S-2 & 65 \\
\hline 3 & S-3 & 60 \\
\hline 4 & S-4 & 70 \\
\hline 5 & S-5 & 75 \\
\hline 6 & S-6 & 80 \\
\hline 7 & S-7 & 70 \\
\hline 8 & S-8 & 75 \\
\hline 9 & S-9 & 80 \\
\hline 10 & S-10 & 70 \\
\hline 11 & S-11 & 85 \\
\hline 12 & S-12 & 80 \\
\hline
\end{tabular}


Khazanah Pendidikan Islam, Vol. 2 No. 2: 77-83

Kalaborasi Penggunaan Strategi Information Search (IS) Dengan Metode Resitasi Terhadap Hasil Belajar Biologi Siswa di SMP Negeri 4 Sungai Penuh

Tomi Apra Santosa dan Reni Lestari

\begin{tabular}{|l|l|l|}
\hline 13 & S-13 & 70 \\
\hline 14 & S-14 & 80 \\
\hline 15 & S-15 & 65 \\
\hline 16 & S-16 & 90 \\
\hline 17 & S-17 & 75 \\
\hline 18 & S-18 & 90 \\
\hline 19 & S-19 & 80 \\
\hline 20 & S-20 & 60 \\
\hline 21 & S-21 & 70 \\
\hline 22 & S-22 & 75 \\
\hline
\end{tabular}

Dari tabel diatas terlihat hasil belajar biologi siswa di kelas eksperimen banyak siswa mendapat nilai tinggi. Nilai - niai siswa dikelas eksperimen rata-rata di nilai KKM. Dan setelah diberikan tes pada pertemuan akhir hasil belajar biologi siswa kelas eksperimen yang menggunakan Information Search diperoleh nilai rata-rata hasil belajar kelas eksperimen adalah 75,78 dengan nilai tertinggi adalah 90 dan terendah 60.

\section{EfektifitasPenggunaan Strategi Information Search Melalui Metode Resitasi Terhadap Hasil Belajar Biologi Siswa}

Adapun data mengenai pottest (hasil belajar) biologi yang diajarkan menggunakan pembelajaran aktif denganstrategi Information Seacrh (eksperimen) dengan diajarkan tanpa menggunakan pembelajaran aktif dengan Information Search (kontrol), disajikan pada tabel 3.

Tabel.3 Skor hasil Posttest pada Siswa kelompok Sampel

\begin{tabular}{|l|l|l|l|l|}
\hline No & $\begin{array}{l}\text { Nomor } \\
\text { Siswa }\end{array}$ & Eksperimen & $\begin{array}{l}\text { Nomor } \\
\text { Siswa }\end{array}$ & Kontrol \\
\hline 1 & S-1 & 60 & S-1 & 50 \\
\hline 2 & S-2 & 65 & S-2 & 40 \\
\hline 3 & S-3 & 60 & S-3 & 55 \\
\hline 4 & S-4 & 70 & S-4 & 60 \\
\hline 5 & S-5 & 75 & S-5 & 40 \\
\hline 6 & S-6 & 80 & S-6 & 65 \\
\hline 7 & S-7 & 70 & S-7 & 50 \\
\hline 8 & S-8 & 75 & S-8 & 60 \\
\hline 9 & S-9 & 80 & S-9 & 40 \\
\hline 10 & S-10 & 70 & S-10 & 55 \\
\hline 11 & S-11 & 85 & S-11 & 45 \\
\hline 12 & S-12 & 80 & S-12 & 45 \\
\hline 13 & S-13 & 70 & S-13 & 60 \\
\hline 14 & S-14 & 80 & S-14 & 45 \\
\hline 15 & S-15 & 65 & S-15 & 70 \\
\hline 16 & S-16 & 90 & S-16 & 70 \\
\hline 17 & S-17 & 75 & S-17 & 50 \\
\hline
\end{tabular}


Khazanah Pendidikan Islam, Vol. 2 No. 2: 77-83

Kalaborasi Penggunaan Strategi Information Search (IS) Dengan Metode Resitasi Terhadap Hasil

Belajar Biologi Siswa di SMP Negeri 4 Sungai Penuh

Tomi Apra Santosa dan Reni Lestari

\begin{tabular}{|l|l|l|l|l|}
\hline 18 & S-18 & 90 & S-18 & 70 \\
\hline 19 & S-19 & 80 & S-19 & 55 \\
\hline 20 & S-20 & 60 & S-20 & 60 \\
\hline 21 & S-21 & 70 & S-21 & 50 \\
\hline 22 & S-22 & 75 & S-22 & 40 \\
\hline
\end{tabular}

Dari hasil belajar inilah yang digunakan dalam menganalisis mengenai pengaruh pembelajaran aktif strategi Information Search terhadap hasil belajar biologi siswa kelas VIII SMP Negeri 4 Sungai Penuh. Dari analisis data diperoleh rata-rata hasil posttest, disajikan pada tabel 4.

Tabel.4 Rata-Rata Posttest Kelompok sampel

\begin{tabular}{|c|c|c|}
\hline Model Pembelajaran & $\mathrm{X}$ & SD \\
\hline Information Search & 75,78 & 9,61 \\
\hline Konvensional & 54,47 & 10.52 \\
\hline
\end{tabular}

Hasil penelitian dan pembahasan merupakan hasil tes setelah dilakukan suatu pemebelajaran yang berbeda antara kelompok eksperimen dan kelompok kontrol. Variabel yang diteliti dalam masalah ini adalah hasil belajar biologi sub bahasan sistem gerak pada manusia pada siswa kelas VIII SMP Negeri 4 Sungai Penuh. Dari hasil penelitian tersebut didapatkan bahwa kelas VIII A sebagai kelas eksperimen dan kelas VIII B kelas kontrol. Berdasarkan hasil ini, kedua kelompok sampel langsung diberi strategi pembelajaran, kelompok eksperimen diajarkan dengan menggunakan pembelajaran aktif Infornation Search dan tanpa diajarkan menggunakan pembelajaran aktif dengan menggunakan strategi Information Search, maka dilakukan tes akhir untuk menguji apakah efektif penggunaan pembelajaran dengan strategi tersebut.

Pembelajaran dengan startegi Information membantu siswa mengembangkan kemampuan mencari ide-ide dan informasi yang berhubungan dengan materi pembelajaran, mengungkapkan ide dengan kata-kata secara verbal dengan membandingkan dengan ide-ide atau gagasan orang lain, membantu agar anak berkerjasama dengan orang lain. Dan dapat memberi rangsangan pada siswa untuk berpikir, meningkatkan kemampuan akademik dan hasil belajar. Pembelajaran yang menggunakan strategi Information Search melalui metode resitasi lebih baik hasilnya dibandingkan dengan tidak menggunakan strategi Information Search melalui metode resitasi. Hal dibutikan dengan pembelajaran strategi Information Search pada kelas eksperimen siswa meraih nilai tertinggi 90 dan tidak ada siswa yang mendapat nilai dibawah 50. Pada kelas kelas kontrol nilai tertinggi adalah 60 dan banyak siswa mendapat nilai 50 .

\section{SIMPULAN}

Berdasarkan penelitian diatas dapat ditarik kesimpulan bahwa hasil belajar siswa yang tidak menggunakan strategi Information Search melalui metode resitasi, nilai tertinggi adalah 70 dan terendah 40. Nilai rata-rata hasil belajar di kelas kontrol 54,47, sedangkan hasil belajar kelas eksperimen yang menggunakan strategi Infomation Search melalui metode resitasi lebih baik daripada hasil belajar kelas kontrol, dimana nilai tertinggi adalah 90 dan nilai terendah 60. Nilai rata-rata hasil belajar kelas eksperimen adalah 75,78. 
Khazanah Pendidikan Islam, Vol. 2 No. 2: 77-83

Kalaborasi Penggunaan Strategi Information Search (IS) Dengan Metode Resitasi Terhadap Hasil

Belajar Biologi Siswa di SMP Negeri 4 Sungai Penuh

Tomi Apra Santosa dan Reni Lestari

\section{DAFTAR PUSTAKA}

Auerbach, A. J. J., \& Andrews, T. C. (2018). Pedagogical knowledge for active-learning instruction in large undergraduate biology courses : a large-scale qualitative investigation of instructor thinking. International Journal of STEM Education, 5(19), 1-25.

Bahtiar, B. K. dan. (2015). PENGARUH STRATEGI THINK-TALK-WRITE (TTW) BERBASIS KONTEKSTUAL TERHADAP KETERAMPILAN PROSES SAINS SISWA KELAS VII MTs NW WANASABA LOMBOK TIMUR TAHUN PELAJARAN 2014/2015. BIOTA: Jurnal Tadris IPA Biologi FITK IAIN Mataram, VIII(1), 43-54.

Effendi, M. (2013). Integrasi Pembelajaran Active Learning dan Internet-Based Learning dalam Meningkatkan Keaktifan dan Kreativitas Belajar Mukhlison Effendi. Nadwa / Jurnal Pendidikan Islam, 7(2), 283-306.

Eka Putri Azrai, Ernawati, G. S. (2017). PENGARUH GAYA BELAJAR DAVID KOLB (DIVERGER, ASSIMILATOR, CONVERGER, ACCOMMODATOR) TERHADAP HASIL BELAJAR SISWA PADA MATERI PENCEMARAN LINGKUNGAN. BIOSFER: JURNAL PENDIDIKAN BIOLOGI (BIOSFERJPB), 10(1), 9-16.

Friedrichsen, P. J. (2018). Negotiating the meaning of Next Generation Science Standards in a secondary biology teacher professional learning community. Journal of Research in Science Teaching, 55(7), 999-1025. https://doi.org/10.1002/tea.21472

Hallström, J. (2015). Drawing the boundary lines of science education. Boundary Lines of Science Education, 44(2), 219-225. https://doi.org/10.1108/HER-02-2014-0008

Hoekstra, A., Beijaard, D., Brekelmans, M., Hoekstra, A., \& Beijaard, D. (2017). Experienced teachers ' informal learning from classroom teaching Experienced teachers ' informal. 0602(July). https://doi.org/10.1080/13540600601152546

Irfan, M. (2019). Pengaruh Penerapan Metode Resitasi Terhadap Hasil Belajar Kognitif Siswa SMA. BIOMA, 1(01), 47-55.

Ismail, B. (2016). Peningkatan Penguasaan Materi Hadits melalui Metode Resitasi pada Mahasiswa PAI FTK UIN Ar-Raniry. Jurnal MUDARRISUNA, 6(2), 219-232.

Nurmiati1, P. A. H. (2019). Pengaruh Penggunaan Metode Resitasi terhadap Hasil Belajar. J-HEST: Journal of Healt, Education, Economics, Science, and Technology, 2(1), 52-57.

Prastowo, A. (2016). Metode Penelitian Kualitatif: Dalam Perspektif Rancangan Penelitian. Jogyakarta: Ar-Ruzz Media.

Rahmawati, F. (2014). PENGARUH STRATEGI INFORMATION SEARCH (IS) DAN LEARNING START WITH A QUESTION (LSQ) TERHADAP HASIL BELAJAR SISWA KELAS VIII SEMESTER GENAP SMP NEGERI 26 BANDAR LAMPUNG. LENTERA, 2, 139-148.

Saebani, B. A. (2008). Metode Penelitian. Bandung: Pustaka Setia.

Sedermayanti. (2011). Metodologi Penelitian. Bandung: Mandar Maju.

Sintang, M., \& Barat, K. (2018). PAUD DUNIA ANAK. Jurnal Pendidikan Anak Usia Dini, 1(1), 1-9.

Try Susanti, Novita Sari, H. (2017). Pengaruh Metode Resitasi Terhadap Hasil Belajar Biologi Siswa Kelas XI Sekolah Menengah Atas Negeri 1 Tanjung Jabung Timur The Effect of Recitation Method on The Student' s Biology Learning Outcomes at Class XI of Senior High School 1 Tanjung Jabung Timu. Biodik Vol, 3(2), 53-59. 